\title{
APPLICATION OF ARTIFICIAL INTELLIGENCE IN DISTRIBUTION OF UNIVERSITY SYSTEM MODEL
}

\author{
Nguyen Hoang Mai \\ Danang University of Science and Technology, Vietnam
}

\begin{abstract}
Higher education and improving the quality indicators of higher education is always a hot problem for all time. Education is the core of the country's society. Over hundreds of years, higher education systems have changed to match the level of civilization, the amount of human knowledge, the new pace of life and the development of information technology. Many higher education methods in developed countries have applied very effectively and met many high educational standards such as ABET, QS - Quacquarelli Symonds, Times Higher Education, SARWU - Shanghai Academic Ranking of World Universities ... Using AI, Big Data has also been applied to minimize time dependence and increase human understanding. From the traditional education model, the world has come to teach online with the application of IoT. In this article, we introduce a new model of higher education that can be applied in the near future to higher-end IoT applications than online, distributed education. We call this the Distributed Higher Education System Model - DUSM. With application of artificial intelligence to make virtual environment in education, we hope have a big change in education to advance quality of education. The analysis of the method will be presented in detail and hopefully it will be quickly applied to suit the capacity of social information technology.

Keywords: education system, distribution of university, virtual classroom, IoT, online learning, AI application, remote education.
\end{abstract}

\section{Introduction}

To talk about DUSM, we first derive from the hilarious traditional higher education (TLM) model shown in Figure 1.
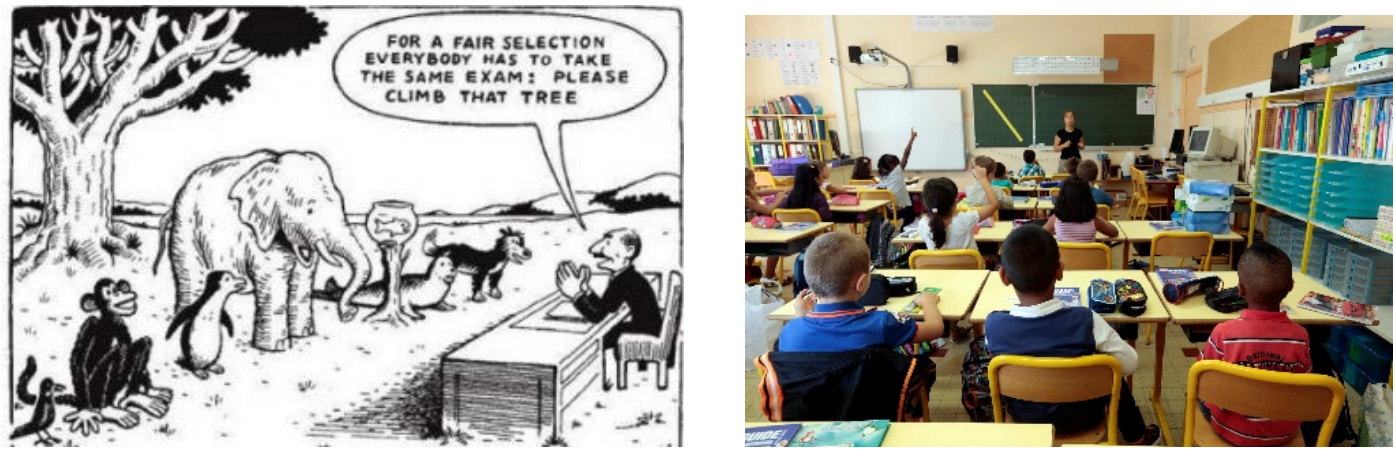

Figure 1 A traditional education model

(C) Rēzeknes Tehnologiju akadèmija, 2020

http://dx.doi.org/10.17770/sie2020vol4.4925 
We can see that with the traditional model, the knowledge that the teacher imparts directly to all students and everyone perceives the same requirements. Therefore the maxim: Everyone is equally smart, only different in time. And we have also seen many limitations of this traditional model, because the knowledge students get will be limited in terms of volume, quality, and opinion and position. Since then, traditional models have been improved and added many features to be able to adapt to new teaching conditions such as using a variety of materials, projectors, dynamic teaching software and tissue, interview, active learning, interactive learning ... But in general, the nature of education does not change, so for a group of students with different personal capacities, it is impossible to make everyone promote. Each person's own creativity to the maximum. It is possible to summarize a university course as shown in Figure 2.

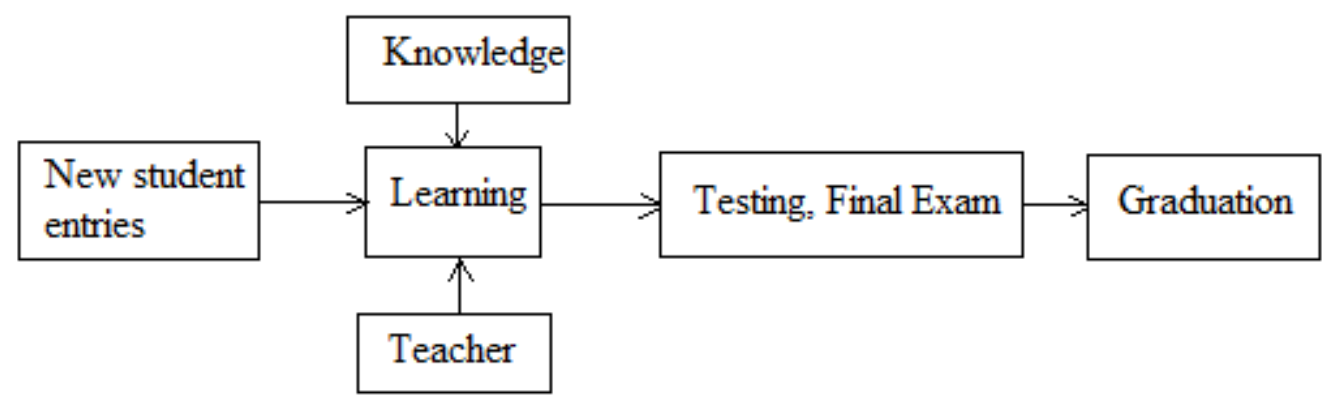

Figure 2 Schedule of TSM

TLM model, many people know its limitations. The most important ones are the following limitations:

- Students do not promote self-discipline at work

- Students do not promote creativity at work and special abilities of each person.

- Do not evaluate the performance of students after graduation. Therefore, the success of a graduate student depends more on luck than inheriting the results of university study.

Entering the era of the internet, many new models have been applied, including online education or online learning (OLM), which has been paid attention and applied by universities, such as Figure 2. In the OLM model, the content of knowledge, teachers, and students are ranked in three independent sources. Therefore the interaction between teachers, students and knowledge is very important. Students need to be proactive in seeking knowledge to turn it into their own, but desperately need support from teachers, "self-interested and have the ability to take hidden actions, there exist complex interactions in the trade-offs among these instruments. We show, however, that such complex interactions produce rather simple and stark implications" (Liang, 2008, p. 809). Online 
learning has greatly reduced the burden of tuition, living expenses, travel and other social security. The process of switching back and forth between the two models is called mixing as in Figure 3.
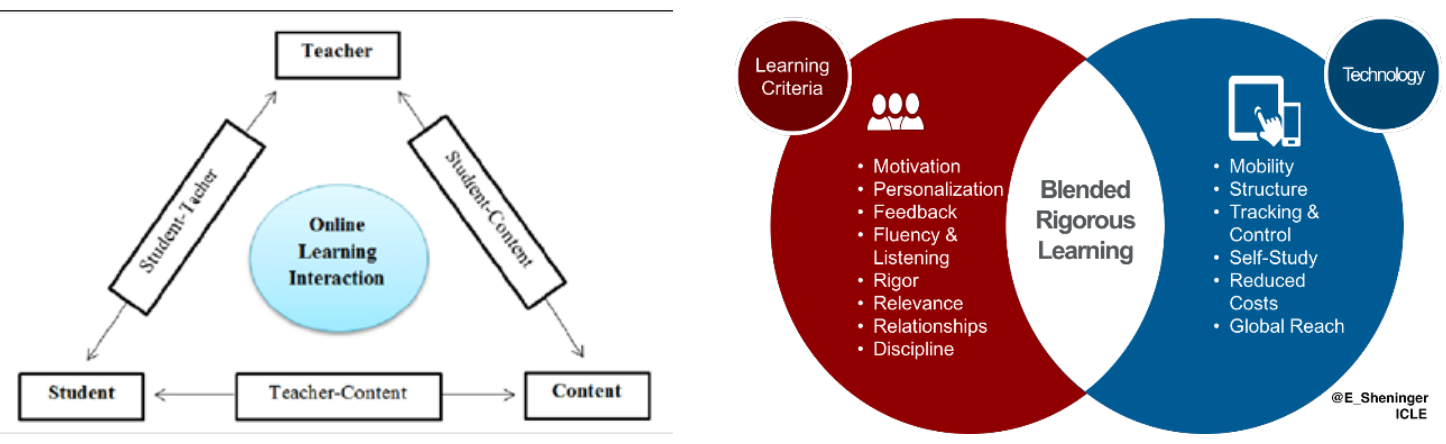

Figure 3 The online learning method

OLM has brought many expected results beyond the TLM and now it is a model applied by universities.

The school's teachers are made up of a team of professors and experts who work for the school or collaborate and are paid on a yearly, monthly or weekly basis or specific topics. In this source, there can be professors from many neighboring universities with the same qualifications who can teach and research together. The basic feature of this workforce is the dependence on a key university and then on the spread. Therefore, the university must have a specific address and a large training service team to take care of all the tasks from admission to admission, curriculum development, program operation, class organization and periodic evaluation, output evaluation.

Students are recruited every year according to the school's registration criteria, based on the school's ability of facilities, professors and the balance of human resources for the labor market, "But surprisingly, a change in affects the optimal quality of the workers and the manager in opposite directions: the firm will hire lower quality workers but better quality managers" (Liang, 2008, p. 808). With OLM, students have the freedom to study but mandate certain deadlines and have assessments to ensure output through a diploma, "The finding is that the contribution from full-time is so big because the famous schools have more attraction and more ability to apply the position to teachers. Besides, the number of full-time teachers is more than part-time teachers" (Liu, 2017, p. 189).

Source of learning content, is knowledge, built from large libraries, cloud data, links between universities, research institutes ... Thereby, teachers and students all have access by individual rights and actively discuss with each other about the limit of learning content as well as content of course and course assessments. 
Access to each other's resources will have an impact on time, "Although no one can expect that educational networks will totally replace the traditional lecture" (Ghosh, 2012, p. 56), personal and social economy, as well as personal rights determined by human rights law. Therefore, there should be many sanctions for this access to ensure fairness but not lose the autonomy and right to perform duties of each source.

The OLM model also has some limitations, as follows:

- Interoperability is limited by the internet, both speed and bandwidth

- Access to data sources is limited due to teacher-student interaction, so it is not flexible.

- The creativity of students is in the control of teachers and social opinion.

- $\quad$ The scope of education is restricted from the initiative initially

- Student learning time is limited by the training time

- The effectiveness of student activities on society in the field of education is not high

- $\quad$ The legal binding between students and the educational environment is too great, resulting in many unnecessary prejudices such as retesting, re-examination and community activities.

- Many students of different ages are not equally educated.

- Self-awareness of students is not high because of the strong ties.

- $\quad$ Do not assess the level of morality and happiness of students.

- $\quad$ Do not evaluate the performance of students after graduation. In other words is like a system without feedback.

\section{Structure of DUSM}

DUSM system as virtual environment of digital education, "There are three primary components in the model: technology, experience, and people”, (Stephen, 2016, p. 1503). It is a combination of environment between real university and cloud environment on the base is high speed internet, it consists the following main components:

- University organizational structure

- Teaching human resource system

- $\quad$ Student resource system

- Document source system

- System of facilities and laboratories

- Health assurance system

- $\quad$ System of support and consulting staff 
- $\quad$ Office staff system

- $\quad$ Financial management system

- Business relationship system

- $\quad$ Legal assurance system

- $\quad$ Education quality assurance system

- Job feedback system after graduation.

This university model guarantees the criteria as a traditional university, but also opens many other criteria as follows:

- Students can study anywhere, as long as there is an internet connection

- Students can study at any time, regardless of whether or not the professor taught at that time

- Students can study at any age to need a major or a certificate of practice

- Students can attend many universities at the same time without having to run to them.

- $\quad$ Save maximum learning costs. Therefore, with a limited amount of money, students can learn as many courses as they need without having to be as expensive as they are today.

- $\quad$ Students can learn for a lifetime when they want.

- Evaluate student performance after learning very accurately. Ensure the reputation of the school.

The basic feature of this system is the strong and deep application of IoT and intelligent management software system. Consider an illustration model as shown in Figure 4.

The university's main campus is an online monitoring server that operates 24 hours a day, ensuring real-time interaction, "Learning must be fully learnercentered, supporting the learner not only in periods of formal training but also in times of need in the workplace", (Stephen, 2016, p. 1505). That means the connection between the school leadership team and all the members is always online. However, in order to reduce the load of the main member, the cloud is divided into smaller clouds for peer-to-peer management, ensuring there is no information bias for any unit. And to be so, obviously the media must be strong. Assuming the school center is located in a server in Riga, but the location of the server does not need to be fixed, a Vietnam student wants to register for a course from March to May. The account to confirm the registration is honest. Thus, the relationship between students and universities will be done through the following steps:

- $\quad$ Students send notice to server.

- $\quad$ Server confirms the account to confirm whether the learning conditions are satisfactory: 


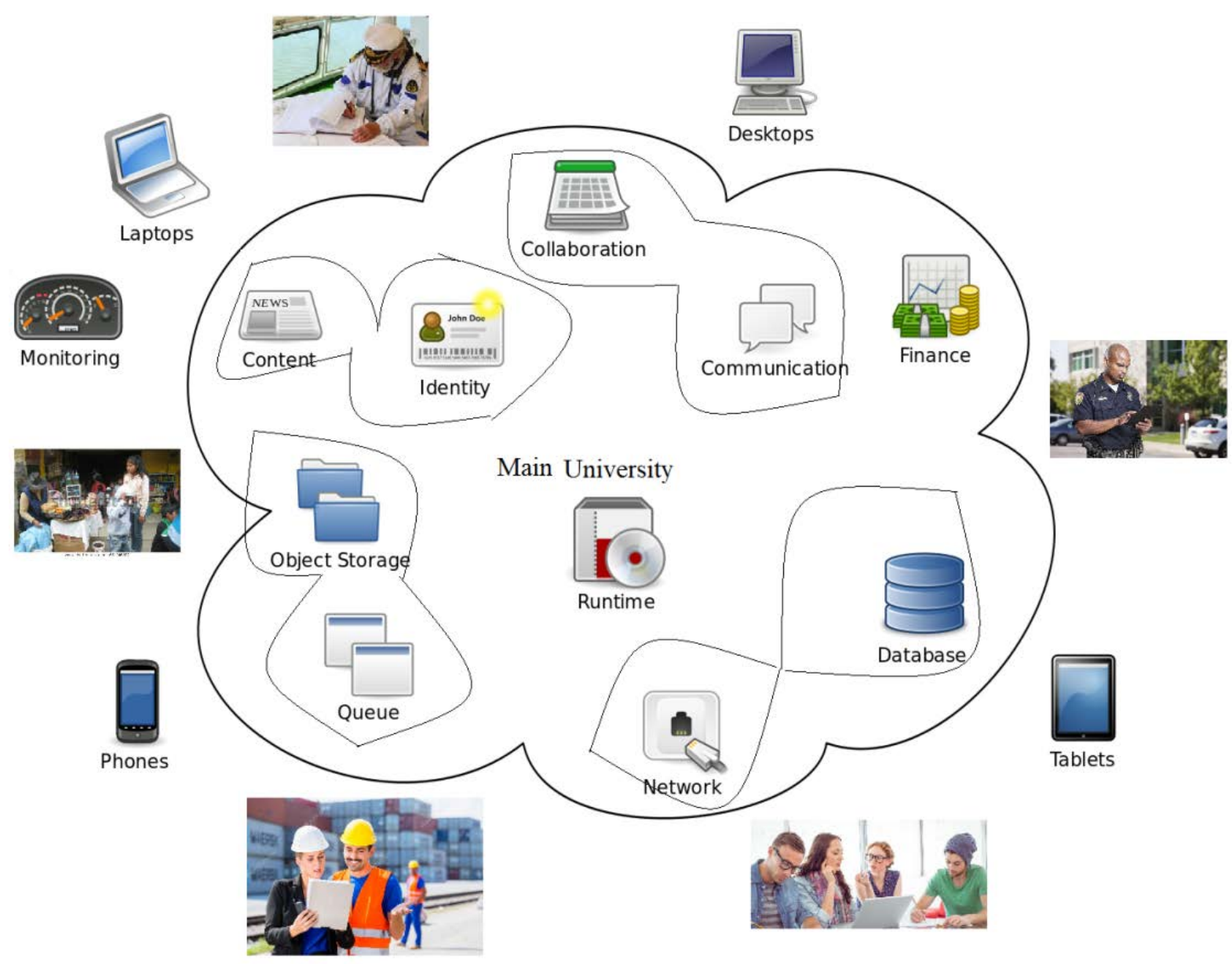

Figure 4 The main environment of DUSM

- If successful, notice of payment, if not successful, consult another subject or notice of refusal.

- Server sends the curriculum content, outline, documents, and online teaching professors for students to choose.

- The student and server agree that the registration of the study has been agreed.

- Server and students agree on the learning interaction between professors and lectures, questions for students to organize their own learning.

- Tuition fee will be deducted directly from your account after confirmation. However, students can also withdraw this tuition if they cancel the course at that time. All information will be collected and so will the learning materials.

All the above activities are done automatically between students and the server. During the learning process, students' questions are classified by AI and given to students answers as same artificial intuitive, "like Simon's experts, have 
a rich body of experience that guides them in scanning their immediate circumstances for opportunities and then rapidly and flexibly responding without the explicit mediation of consciousness to generate educational value”, (Waks, 2006, p. 385). Some questions are beyond the capabilities of AI, the software will pass to the professor and he will answer this question into the database. It should be noted that there is no set standard of questions and answers. The AI only analyzes in the heart the question and answers according to the focus, not completely the professor's answer. In general, the AI "buys" the professor's answer and "resells" it to the student. Such a professor's answer can provide thousands of students at different times. That is a big difference compared to OLM or TLM.
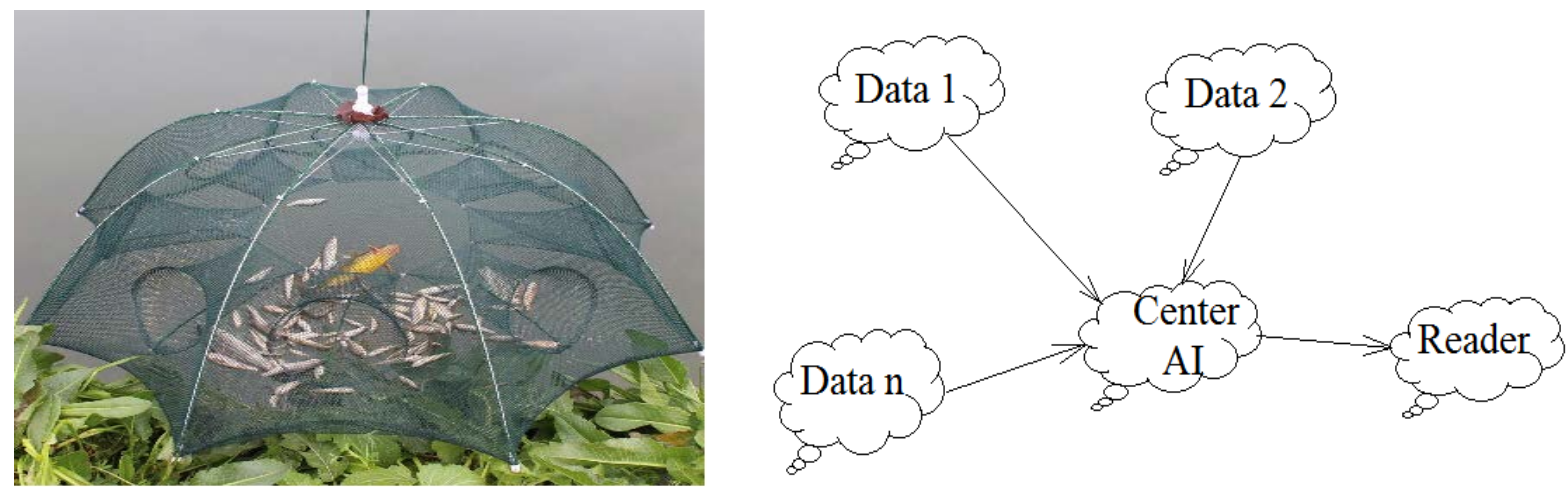

Figure 5 The collection data for human in DUSM

- $\quad$ DUSM libraries are located in many different servers in the world, but they are linked together like a net and the bottom of the net is the central library of the school. We can imagine as shown in Figure 5. Not all the nets have fish, but when we shake the bottom of the net, the fish will fall to the bottom one by one. The same goes for a DUSM library, whichever information is needed, the server will notify and the libraries will send information back, and the reader will choose to get the most logical information like catching the biggest fish under the classification whose. That way of avoiding students will spend too much time without finding the most useful information.

- For experiments, the experiment room is organized 24 hours a day. When a student needs an experiment, they send a message to the server and ask for confirmation. The server will search for appropriate laboratory equipment in a "shared resource" structure, meaning that there will be many testing centers capable of providing equipment and tests that are not part of a university. These are IoT test devices, meaning students will compute algorithms with data, send to devices, 
devices will receive and perform experiments, then take the data and send it back to students for analysis. The student does not need to know where the laboratory is located, but he can watch the experiment process online on the $\mathrm{LAB}$ video online at the time. In general, the $\mathrm{LAB}$ system as network with links to connect LAB rooms. If you want to do experiment anything, the network nodes will contact as same collaboration and find a best $\mathrm{LAB}$ to you. Your job is preparing experiment lecture and time to participate into $\mathrm{LAB}$, payment learning fee and do it. After finish experiment, you will receive data and apply into your project. A good system of Danang University (DUT) is a LMS (Learning Management System) used to manage lectures and provide online learning for students has been in operation for 5 years at DUT (2015-2019). Many students and faculty use and have initially brought good results. Another application is remote protection of the thesis, used when students practice in businesses and not about protection at the school, then the protection is done online synchronously between the school, business and Students who have been using DUT since 2018 also have very good results. We continue improve many applications to develop system to DUSM in near future.

- For theoretical learning, virtual professors will teach students on smartphones or laptops, or other audio-visual devices such as televisions. The interaction between professor and student through AI is mediated as analyzed above. Students can ask questions directly to receive answers without wasting time on lectures. This allows the professor to still lecture but the student will still hear the professor's answer even if the professor did not respond at that time. All shown as Figure 6.

- Evaluation activities are conducted between server and students. Students self-schedule the exam for the server and after agreeing on the schedule, the server ask questions and monitor the student's exam process through the webcam and image processing software. Questions are arranged automatically and students will answer in either multiple choice or essay, or oral format. The AI software will evaluate the speed of answers and ask additional questions for students to see if students do it themselves or have many supporters around. This is an AI trick and is not informed in advance. Students take the exam but do not need to go to class but can be anywhere and take the exam whenever students can arrange it.

- The business system is linked to the database of the school server and constantly updates information from the business through other 
agencies such as tax and auditing. Students who want to do internships with businesses are also through university recommendations but are also under the control of the school server. Students can register for an internship with the business according to the plan set out by the business or student's request. The server of the university only monitors the internship time through questions about internship content, internship time and practice demonstration, students' answers are specific answers for internships and accuracy. Receipt of the business is the final result.

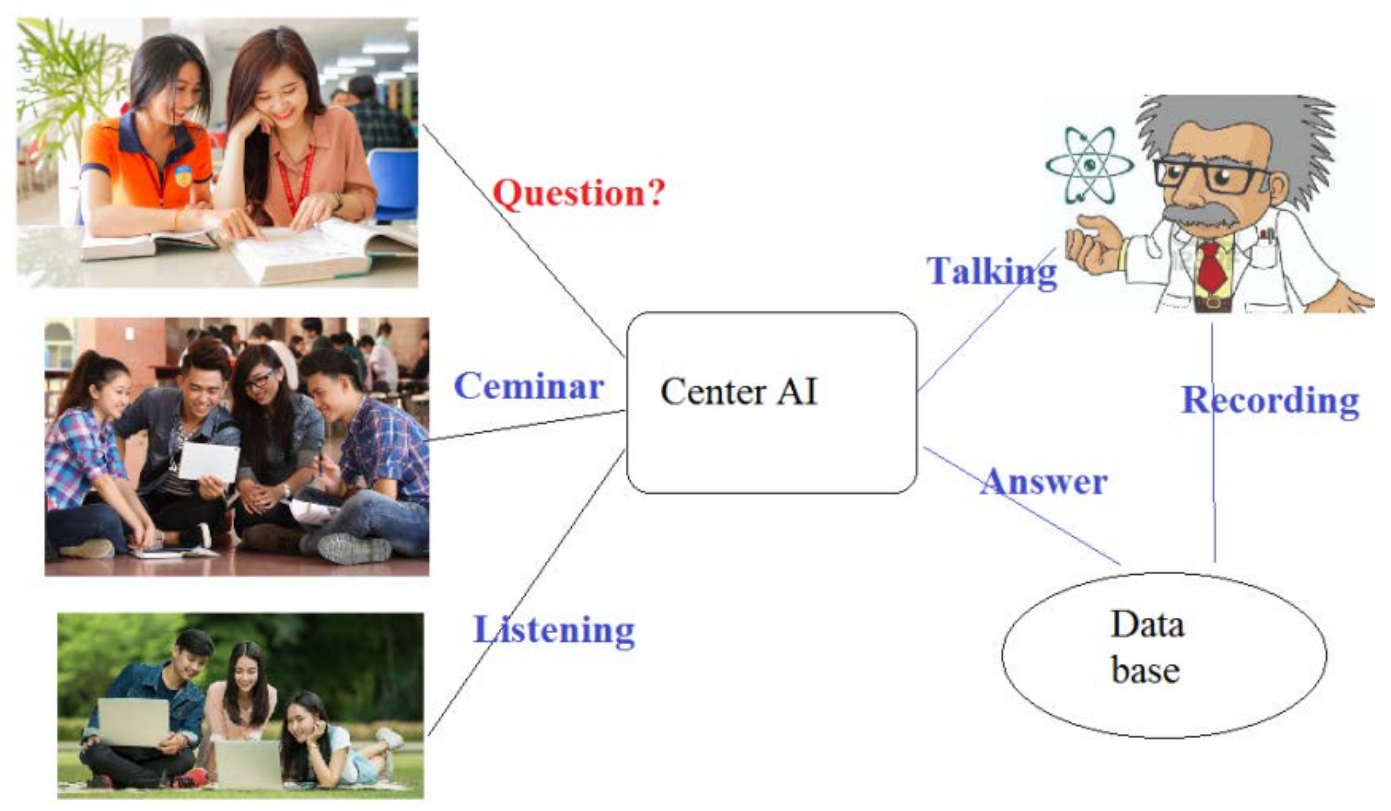

Figure 6 Relation environment of education

\section{Algorithm of AI in Education}

There are many algorithms of AI to apply in DUSM. We start with AI in education in some question and answer as inference.

$$
\begin{aligned}
& \text { Word } 1-\text { word2 - word3 = x(n)-y(n)-z(n) } \\
& \mathrm{x}(\mathrm{n})=\{\mathrm{x}(\mathrm{k})\}=[\mathrm{x}(1) ; \mathrm{x}(2) ; \ldots ; \mathrm{x}(\mathrm{p})] \\
& \mathrm{y}(\mathrm{n})=\{\mathrm{y}(\mathrm{k})\}=[\mathrm{y}(1) ; \mathrm{y}(2) ; \ldots ; \mathrm{y}(\mathrm{q})] \\
& \mathrm{z}(\mathrm{n})=\{\mathrm{z}(\mathrm{k})\}=[\mathrm{z}(1) ; \mathrm{z}(2) ; \ldots ; \mathrm{z}(\mathrm{m})]
\end{aligned}
$$

So, we have a maximum number of ability combination is $\mathrm{N}=$ p.q.m, but only some ability is able to use true state. From that, we can illustrate model as figure 7.

We can see all state as ANN, but is not same, in final result, only some event is true and AI will choose best answer. There is not feedback in this case but there a direction pass any word. The choice of AI evaluated by MIN-MAX inference of 
experiment AI has learned after finished growth. The adaptation of question to content of lecture of program is maximum weight function or target function. With function as follows:

$$
\begin{gathered}
\mathrm{f}=\operatorname{MAX}\{\operatorname{MAX}\{\operatorname{group}[\mathrm{x}(\ldots \mathrm{k}) \cdot \mathrm{y}(\ldots \mathrm{m}) . \mathrm{z}(\ldots \mathrm{l})]\} ; \operatorname{MAX}\{\operatorname{group}[\mathrm{x}(\mathrm{k}+1 \ldots) . \\
\mathrm{y}(\mathrm{m}+1 \ldots) \cdot \mathrm{z}(\mathrm{l}+1 \ldots)]\} ; \ldots \operatorname{MAX}\{\operatorname{group}[\ldots]\} \ldots\}
\end{gathered}
$$

In that, we calculate group of elements and gradient of them in condition together. The final result is choice a best element to solve process.

To solve this difficult, we take out team group optimal method. In that, the equivalent elements will arrange in a team, by gradient criterion described in high order derivative equations. The selection of the main element to go to target is a weight function.

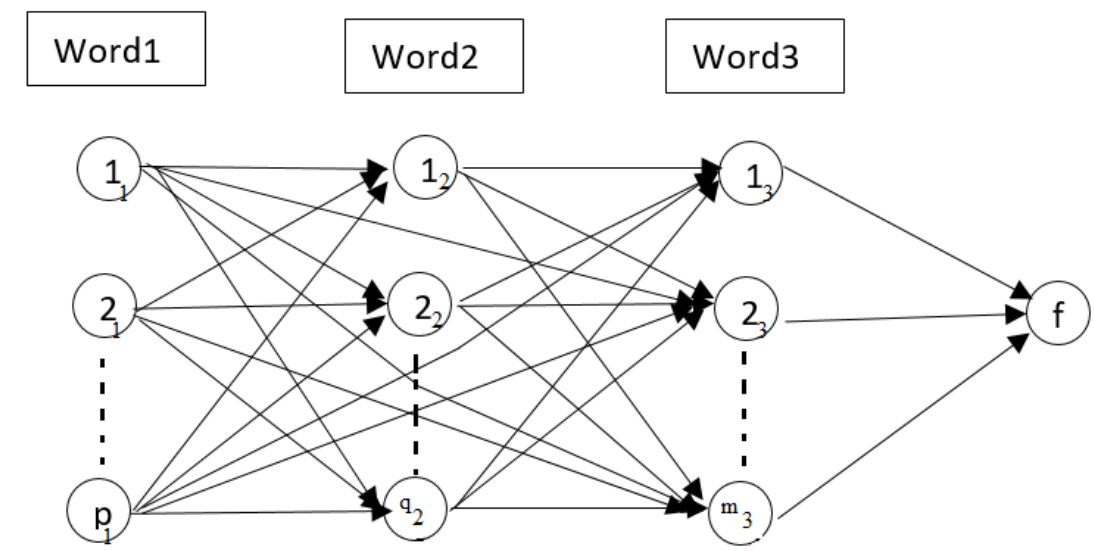

Figure 7 Analyze information in DUSM

The connection of DUSM has filtering property to find good way and guard final result. If student has a long question, AI will analyse as same process and insurance balance property for every one and every time.

\section{References}

Ghosh, S. (2012). Open and distance learning (ODL) education system: past, present and future - A systematic study of an alternative education system. Journal of global research I computer science, 3(4), April 2012.

Liang, P.J. (2008). Optimal Team Size and Monitoring in Organizations. Carnegie Mellon University. The account review, 83(3), 789-822.

Liu, Y. (2017). The Equality of Distribution of Education Resources-The Case of 96 Universities in the US. Open Journal of Social Sciences, 5, 180-190. Retrieved from http://www.scirp.org/journal/jss

OECD. (2012). Equity and Quality in Education. Supporting Disadvantaged Students and Schools, OECD Publishing. DOI: http://dx.doi.org/10.1787/9789264130852-en 
SOCIETY. INTEGRATION. EDUCATION

Proceedings of the International Scientific Conference. Volume IV, May $22^{\text {th }}-23^{\text {th }}, 2020.516-526$

Stephen, V. (2016). Distributed Learning: A Flexible Learning and Development Model. ELearn: World Conference on E-Learning in Corporate, Government, Healthcare, and Higher Education, At Washington, DC US.

Unicef. (2015). Education and Equity, The Investment Case for Education and Equity. Retrieved from https://www.unicef.org/publications/files/Investment_Case_for_ Education_and_Equity_FINAL.pdf

Waks, L.J. (2006). Intuition in Education: Teaching and Learning without Thinking. Retrieved from https://www.researchgate.net/publication/277178951, Philosophy of Education Temple University. 